\title{
Dr. Thomas Friedberg (January 24, 1951-April 22, 2009)
}

\author{
Roland Wolf $\cdot$ Franz Oesch
}

Received: 25 August 2009/Accepted: 27 August 2009/Published online: 11 September 2009

(C) Springer-Verlag 2009

It is with great sadness that we report here on the sudden and tragic death of Dr. Thomas Friedberg. ${ }^{1} \mathrm{He}$ was a member of the editorial board of this journal and we are grateful that the editors invited us to contribute an obituary. Thomas was born on January 24, 1951, in Mainz, Germany. In 1978, he attained his degree ("diploma") in chemistry, receiving the highest possible distinction, from the University of Mainz. His work from this period included pioneering studies on pesticides in tumor susceptible versus resistant mice strains. For one of the publications resulting from his work of this period he received the American Society of Pharmacology and Experimental Therapeutics "Best Paper Award", undoubtedly a great honor for a non-American working outside the United States. In 1981, he completed his Ph.D. on characterizing the biochemical and toxicological properties of a key detoxication system of mammalian organisms including humans, the glutathione S-transferases under the supervision of one of us (Franz Oesch). During his Ph.D. studies, Thomas also performed pioneering work on the detoxification of metabolites in polycyclic aromatic hydrocarbons together with Hansruedi Glatt. In 1982, he moved to New York as a postdoctoral fellow where he joined the laboratory of Professor Gert Kreibich at the New York University (NYU) Medical Center's Department of Cell Biology. This sojourn in the United States was highly successful for a

\footnotetext{
R. Wolf $(\bowtie)$

Biomedical Research Institute, University of Dundee, Ninewells Hospital and Medical School, Dundee, UK

e-mail: c.r.wolf@dundee.ac.uk

F. Oesch

Institute of Toxicology, University of Mainz,

55131 Mainz, Germany

e-mail: oesch@uni-mainz.de
}

number of reasons. Thomas was the first person to isolate cytochrome P450 cDNAs from the CYP2C gene family, the clones at the time being called TF1 and TF2 for his initials. As part of his research in NYU, he also carried out extraordinary studies on the factors defining the homo- and hetero-dimerization of glutathione S-transferase proteins. In 1984, Thomas returned to Franz Oesch's Institute of Toxicology in Mainz.

During that period Thomas made a number of significant discoveries: the detection of drug-metabolizing enzymes in several liver cell types other than hepatocytes; the development of heterologous systems for the expression of drugmetabolizing enzymes in mammalian cells and their subsequent use to establish the role of specific enzymes in the metabolic activation versus detoxication of carcinogens; the isolation of several hepatic proteins related to microsomal epoxide hydrolase (published in this journal); the identification of a single membrane anchor sequence of microsomal epoxide hydrolase and its implication for drug metabolism pathways; the repression of the crucial detoxication system, glutathione S-transferases by foreign compounds; the production of site-specific antibodies to distinguish the function of structurally very closely (more than $98 \%$ homology) related types of cytochrome P450; as well as the discovery of a novel cytochrome P450 which is expressed in the sebaceous glands but not in the liver.

In 1993, Thomas took up a position as senior lecturer in the Biomedical Research Centre at the University of Dundee. One of his numerous successful activities was the development of a collaborative research program with the pharmaceutical industry on the heterologous expression of human cytochrome P450s in E. coli, where he developed reagents that are now widely used in the pharmaceutical

$\overline{1}$ A similar obituary has been published in the 2009 ISSX newsletter. 
industry. Thomas was subsequently involved in other important collaborations with the pharmaceutical industry and completed compelling work on the relationship between cytochrome P450 expression and drug transporter activity in defining drug metabolism and chemical toxicity.

Throughout his career Thomas supervised many Ph.D. students who have gone on to forge successful careers in academia and industry and some of his publications belong to the most cited articles in his field of research.

We will remember Thomas not only for his scientific contributions but also for his willingness to help, for his collegiality, and, importantly, for his good humour. One outstanding character trait was his willingness and ability to smooth tensions in the lab by understanding different interests and positions. Thomas was a scientific enthusiast and was involved passionately in his research work. He was a member of the Council and Nomination Committee of the International Society for the Study of Xenobiotics
(ISSX) and a frequent speaker at international meetings. Away from work, Thomas loved outdoors pursuits, particularly skiing, hiking, and walking in the hills, and he greatly enjoyed a glass of German beer. We, as Thomas' colleagues and friends, will remember him for all the attributes mentioned above and for the fact that he never criticized his colleagues. Although perhaps not one of the most organized people in the world, his absent-mindedness in itself was but one of his many endearing qualities. Certainly his larger-than-life presence and hearty laughter are noticeably absent from the Biomedical Research Institute and serve as a poignant reminder of the loss of a great colleague and friend. Thomas will undoubtedly be sorely missed by his scientific colleagues and very large circle of friends worldwide.

August 2009 